This item was submitted to Loughborough's Research Repository by the author.

Items in Figshare are protected by copyright, with all rights reserved, unless otherwise indicated.

\title{
Discursive psychology: mind and reality in practice
}

PLEASE CITE THE PUBLISHED VERSION

PUBLISHER

Palgrave Macmillan @ The authors

VERSION

AM (Accepted Manuscript)

LICENCE

CC BY-NC-ND 4.0

REPOSITORY RECORD

Potter, Jonathan, and Alexa Hepburn. 2019. "Discursive Psychology: Mind and Reality in Practice”. figshare. https://hdl.handle.net/2134/9355. 
This item was submitted to Loughborough's Institutional Repository (https://dspace.lboro.ac.uk/) by the author and is made available under the following Creative Commons Licence conditions.

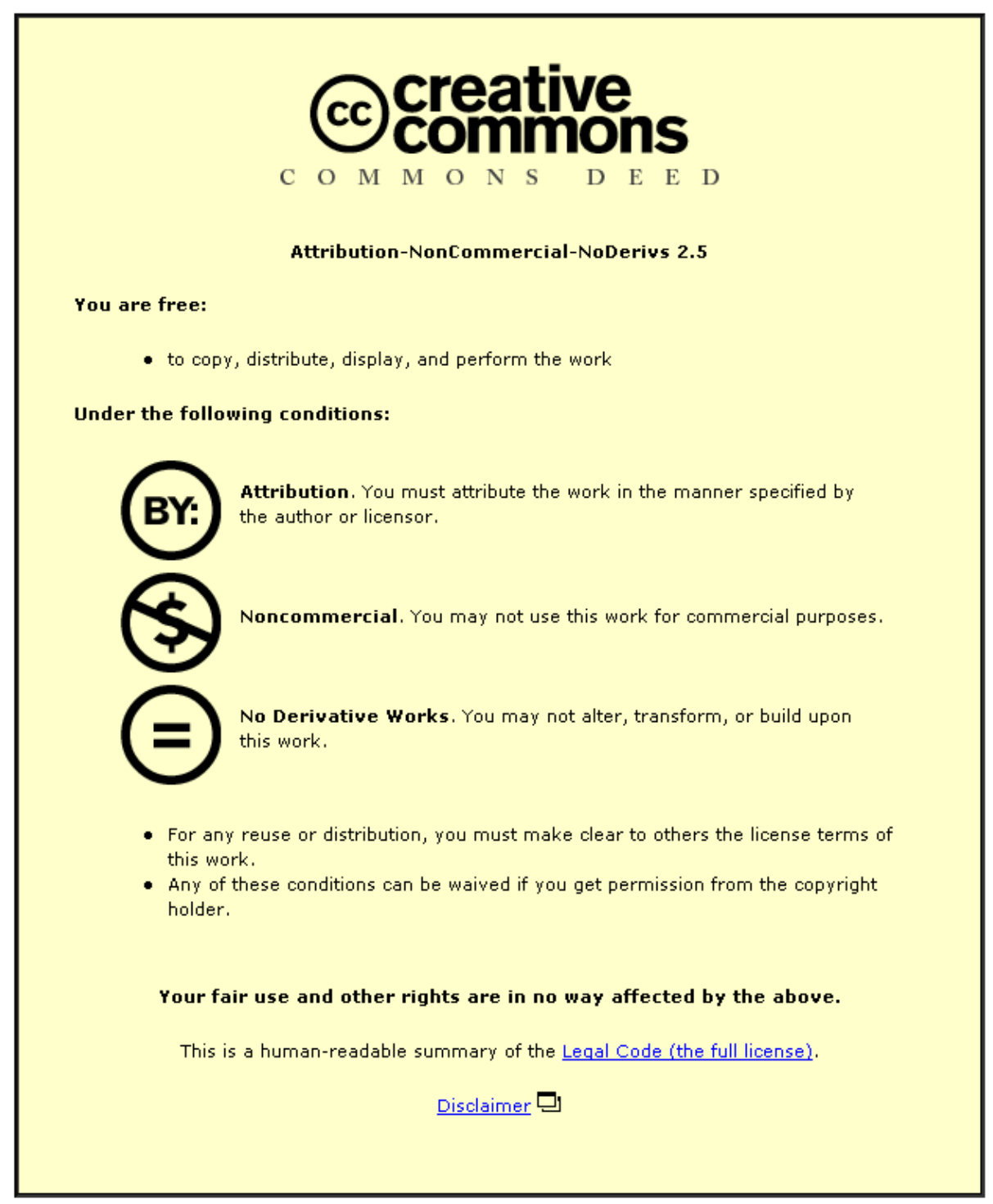

For the full text of this licence, please go to: http://creativecommons.org/licenses/by-nc-nd/2.5/ 


\section{DisCURSIVE PSYCHOLOGY:}

\section{Mind AND ReALITY In PRACTICE}

\section{J onathan Potter \& Alexa Hepburn}

Discourse and Rhetoric Group

Department of Social Sciences

Loughborough University

Loughborough

Leicestershire, LE11 3TU
Email:J.A.Potter@lboro.ac.uk

Email:A.Hepburn@lboro.ac.uk

Tel: $\quad 01509223384$

Fax: 01509223944

Acknowledgements

Wordcount: 8769

To appear as: Potter, J . \& Hepburn, A. (forthcoming). Discursive psychology: Mind and reality in practice. In A. Weatherall, B. Watson, \&C. Gallois (Eds). Language, discourse and social psychology. London: Palgrave. 


\section{Discursive Psychology:}

\section{Mind and Reality in Practice}

This chapter will introduce the perspective of discursive psychology. It will introduce its basic theoretical and methodological features, and then flesh them out using a series of recent studies of a child protection helpline. Discursive psychology will be used to make sense of a range of features of what happens on the helpline. In turn, the analysis of the helpline will be used to illuminate the nature of discursive psychology (henceforth DP).

DP is a perspective that starts with the psychological phenomena as things that are constructed, attended to, and understood in interaction. Its focus is on the ways descriptions can implicate psychological matters, on the ways psychological states are displayed in talk, and on the way people are responded to as upset, devious, knowledgeable or whatever. It thus starts with a view of psychology that is fundamentally social, relational and interactional. It is not just psychology as it appears in interaction; rather, it understands much of our psychological language, and broader 'mental practices', as organized for action and interaction. It is a specifically discursive psychology because discourse - talk and texts - is the primary medium for social action.

Most research in modern cognitive and social psychology takes as its central topic mental entities, representations or broad processing systems. Entities such as scripts, schemata, attitudes, attention, theory of mind, perception, memory, and attribution heuristics figure large in such research. DP is not a direct counter to such research (although, as we will show, it raises a range of questions with how such things are theorized and operationalized). Its aim is rather different. Rather than 
trying to get inside people's heads to get at these entities the focus is on discourse: talk and texts in social practices. It looks for psychology in a completely different place.

Take the central and traditional social psychological notion of attitudes for example, rather than considering attitudes as mental entities that drive behaviour (as they are conceptualized in social cognition, such as in Ajzen's (1991) well known theory of planned behaviour) in DP they are respecified in terms of a broader concern with the construction of evaluations and what evaluations are used to do. For instance, in DP work has studied the way food evaluations figure as part of the activity of complimenting the cook, as inducements to an adolescent girl to eat, or as the building blocks of a complaint about child abuse (Wiggins \& Hepburn, in press; Wiggins \& Potter, 2003). Conversely, DP work has studied how the absence of evaluation, and specifically the absence of an individual's attitude, is constructed, such as when making negative comments about minority groups (Potter \& Wetherell, 1988; Wetherell \& Potter, 1992). So in environments where issues of prejudice and discrimination are live it can be important to not have a (negative) attitude, but merely to be objectively describing the world (including any putative negative characteristics of minority groups). Indeed, in DP the whole distinction between what is subjective (psychological) and objective (real, in the world) is seen as something that is constructed, attended to and reworked in discourse (Edwards, in press; Potter, 1996).

Put briefly, DP treats discourse as having three key characteristics. First, it is action-oriented. Discourse is recognised to be primarily a practical medium and the primary medium for action. Second it is situated. It is organized sequentially, such that the primary environment for what is said is, typically, what was said just previously, and what is said sets up, but does not determine, what will be said 
immediately following it. It is situated institutionally in the sense that it is embedded in, and often constitutive of, practices such as news interviews, relationship conflicts or air traffic control instructions. It is situated rhetorically in the sense that constructions may be oriented to counter relevant alternatives. Third it is both constructed and constructive. It is constructed in the sense that discourse is put together from different elements such as words, categories, commonplaces, interpretative repertoires and other elements. It is constructive in the sense that versions of the world, of actions and events, of mental life and furniture are put together and stabilized in talk.

Methodologically, discursive psychology uses careful and systemic analysis of discourse to reveal phenomena of this kind. DP is a package - its topic, discourse, requires an analytic approach that can do justice to the nature of discourse. Discourse works neither in the manner of a mechanical system of weights and pulleys, nor in the manner of a linguistic grammar book with formal rules. The traditional psychological tools of experiment and survey are not tuned for this job. In this chapter we will not say much about methodological issues, although they may become apparent as we described the development of research - for more elaborate coverage of methodological issues in DP see Potter (2003a,b, 2004) and Wood and Kroger (2000). But first some context and history.

\section{A Brief History of Discursive Psychology}

Discursive psychology emerged out of the specific strand of discourse analysis that developed in social psychology in the 1980s. This in turn had its somewhat convoluted roots in the sociology of scientific knowledge, post-structuralism, linguistic philosophy, ethnomethodology and conversation analysis. Let us briefly sketch the outlines of this early work, starting with Potter and Wetherell (1987) 
which is probably the work that did most to establish the power and nature of a discourse approach to psychological issues.

This book laid out a discourse analytic approach to the psychological topics familiar from traditional social psychology textbooks, such as attitudes, accounts, the self, categories and representations. In each case the focus was on the way these entities figured in interaction. For example, it drew on Harvey Sacks' (1992) work on membership categories to offer a critique of the standard treatment of categories as mental entities that organize (and distort) perception and it offers one of the first attempts to apply conversation analysis to a social psychological topic in its critical consideration of the literature on accounts.

One of the central analytic notions of Potter \&Wetherell (1987) was that of interpretative repertoires, that is interrelated sets of terms, used with some stylistic coherence, and often organized around particular tropes or metaphors. This notion comes from Gilbert \& Mulkay's (1984) study of the different repertoires that scientists use to construct their social world when they are arguing with one another. It was developed in Wetherell \& Potter (1992) which studied the way Päkehä New Zealanders constructed versions of social conflict and social organizations to legitimate particular versions of relations between groups. Much of the interest was in ideological questions of how the organization of accounts, and the resources used in those accounts, could be used to help understand the reproduction of broad patterns of inequality and privilige.

This work also drew on Billig's (1987[1996]) rhetorical psychological notions, including the idea of a rhetorical commonplace. Billig suggests that for any culture at any time in history there will be certain phrases or sayings that have a familiar or taken-for-granted quality. Wetherell \& Potter (1992) show how Päkehä New Zealanders draw on a contradictory weave of commonplaces to construct arguments 
against social change and critique. Billig (1992) also used the notions of rhetorical commonplaces and interpretative repertoires in his study of the way ordinary British people talk about the Royal Family. He showed the way these linguistic resources were fundamental for reproducing certain assumptions about nationality, privilege, equality and change. He suggested that participants are performing 'acts of settlement' in their talk, settling 'ordinary people down into their place within the imagined national community' (Billig, 1992: 22). For an overview of these major early studies see Hepburn (2003, ch. 7).

While these studies are commonly described as discourse analysis Edwards \& Potter (1992) laid out the basics of a more distinctive discursive psychology. Part of the reason for this naming was simply to provide a more clear-cut differentiation from the confusing range of approaches dubbed discourse analysis from across the social sciences (see J aworski \& Coupland, 1999; Wetherell, et al., 2001). Discursive Psychology was distinctive in applying ideas from discourse analysis specifically to psychological issues. It took as its topic memory and attribution and offered a respecification of both topics in terms of discourse practices - rather than considering them as mental entities and processes it treated remembering in terms of situated descriptions and attribution in terms of the way descriptions are organized to manage speaker accountability and to assign blame. A central feature of the work involved taking research in memory and attribution which either used natural interaction or addressed linguistic issues, and showing how its conclusions were distorted by its failure to address the practical nature of language use.

This strand of work was developed more fully in two subsequent works. Potter (1996) offered a systematic rethink of constructionism. This was organized around a consideration of the way descriptions are constructed from different resources (words, membership categories, commonplaces, interpretative repertoires, 
etc.) and the way these descriptions are organized to perform particular actions. Moreover, it focused on the procedures through which versions of events and actions are produced as literal, credible and independent of the speaker. That is, how they manage the 'dilemma of stake' (Edwards \& Potter, 1992) that means all discourse can potentially be treated as motivated or interested in some way.

Edwards (1997) is the other major work. It too considered the role of descriptions. However, its particular focus was on the way descriptions of mental life (categories, emotions, and so on) in all their different forms become parts of particular practices. For example, Edwards noted that when describing actions there are a range of different options. One form of description presents them as tied to the speaker and her or his dispositions. Yet another common form of description presents actions as standard or regular. Both are often highly indirect. Edwards called such descriptions 'script formulations' (1994, 1997). A key feature of such descriptions is that they manage accountability (or 'attribution' in the traditional social psychological language). Presenting an action as scripted presents it as not requiring an explanation making reference to the speaker; however, if an action is presented as deviating from script in some way this can be produced as dispositional, and therefore to be explained by reference to the actor. Moreover, Edwards argues that cognitive psychology approaches that look for mental scripts (as frames for information processing) can easily miss the performative nature of the script talk that appears in research materials.

It is notable that as DP developed out of a rather broader discourse analytic approach there has been much less of an emphasis on the analysis of qualitative interviews. Although such work can still be pertinent and address important issues (Edwards, 2003; Lawes, 1999; Wetherell \&Edley, 1999), its limitations have been increasingly apparent (Potter \& Hepburn, 2005). At the same time, if records of 
natural interaction can be analysed so effectively, the reasons for using a research procedure which embodies a range of troubles become less telling.

\section{The Disciplinary Context of Discursive Psychology}

It is worth briefly distinguishing DP from approaches which it shares some similarities and differences with. In particular, we will consider sociolinguistics, social psychology of language and conversation analysis (henceforth CA). Let us start with sociolinguistics and the social psychology of language. One simple way of separating these approaches is to consider the different ways that they conceptualize language. In much sociolinguistics language appears as a dependent variable, some feature of language such as lexical choice or accent is associated with a variable of interest such as gender, social groups, status, class or something similar. Social psychology also often treats features of language as dependent variables. For example, work in the 'communication accommodation' tradition has studied the way speaker's accents modify according to the group membership of the addressee, modelling this according to a social psychological process model (see chapter 11). Work in both traditions often assumes a telemental view of language, in which it provides a medium for transferring thoughts from one mind to another (Harris, 1988), and such work often assumes that words are associated with mentally encoded categories or concepts.

Discursive psychology does not start out by rejecting such views (although there are pertinent philosophical and sociological critiques - Wittgenstein, 1953; Coulter, 2005). Rather, it brackets issues of cognitive process and reference off, so that it can start somewhere different. Its focus is squarely on language use - hence the discursive psychology rather than psychology of language or something similar. In particular, its focus is on discourse practices that are involved in psychological 
orientations and constructions, or draw on psychological terms. It is important to note, however, that DP provides a sideways respecification and reworking of the whole domain of the psychological, which simultaneously expands it and shrinks it, and questions the very idea that there is a clearly bounded class of psychological terms. For extended overviews of the difference between DP and sociolinguistics Potter \& Edwards (2001a); and for DP and social psychology of language see Edwards \& Potter (1993), Potter \& Edwards (2001b) - and the debate between Schmid \& Fiedler (1999) and Edwards \& Potter (1999).

DP's relation to CA is a complex one. CA currently offers the most developed and sophisticated approach available to what would traditionally have been called linguistic performance. DP draws heavily on both the analytic tradition of CA and its specific findings. Sacks' (1992) foundational work on CA also offers a sophisticated approach to psychological explanations and language (see Potter \& te Molder, 2005 for overview). However, there are at two significant areas where there is a difference in emphasis and even potential tension.

First, DP has built a systematic approach to relating the construction of descriptions to the actions that they are involved in. For example, it has studied the way constructions of emotions such as anger in relationship counselling can be part of assigning problems to individuals, nominating them as the party requiring change (Edwards, 1995, 1997). Note that such constructions are mutually inferential people construct versions of their own thoughts, memories, feelings and so on as part of establishing versions of events or settings and vice versa. This constructionist theme is much less central in CA compared to DP. Moreover, DP draws on the rhetorical tradition of Billig (1996). This highlights the way descriptions are assembled in ways that counter actual or potential alternatives versions. DP is distinctive from other constructionist traditions in its focus on the business of 
constructing versions in talk and texts, and its emphasis on the way constructions are parts of situated practices.

Second, DP is a systematically non-cognitive approach. That is, it brackets off questions about the existence (or not) of cognitive entities and processes whether they are part of one of the range of technical perspectives that make up modern psychology, or are part of the lay ontologies of mind that embedded in particular cultures. Its focus is squarely on cognitive entities as they are constructed in and for public, interactional practices. Note that this includes studying the way practices such as therapy or parenting may draw upon basic cognitivist or psychological distinctions, such as between surface and depth, or between public and private. For the most part, CA too has been a non-cognitivist enterprise. However, CA researchers have a more ambivalent approach to cognition, sometimes attempting to connect interactional phenomena to what they understand as cognitive phenomena (for an overview of these issues see papers in te Molder \& Potter, 2005, and the debate between Coulter, 1999, and Potter \&Edwards, 2003).

So far we have overviewed general features of DP. We now want to go on and illustrate its operation through specific analyses of particular topics.

\section{Discursive Psychology and Child Protection}

We will base our discussion on a programme of work conducted with the UK NSPCC (National Society for the Prevention of Cruelty to Children). We will focus in particular on studies that can be used to show the contrasting treatment offered to classic psychological concepts: cognition (knowledge, attitude), perception, and emotion. The aim in each case will be to show how a very different understanding is provided by starting with how these things arise in discourse as practical issues to be addressed by participants. Note that we have deliberately selected notions such as 
emotion and perception that are often treated as prior to, and separate from, what would traditionally be understood as linguistic phenomena. These are hard cases' for an approach that focuses on talk and text.

The NSPCC is the major child protection charity in the UK. Central to their work is a 24 hour National Child Protection Helpline that receives several hundred thousand calls each year. This is legally required to pass credible reports of abuse to either social services or the police, whether the caller wishes it or not. The helpline also provides free counselling, information and advice to anyone concerned about a child at risk of ill treatment or abuse, or to children themselves who may be at risk. It is staffed by trained social workers with at least 3 years field experience of working in child protection; they work under the title Child Protection Officer (henceforth $\mathrm{CPO})$.

Our research is based mainly at the NSPCC's London centre. Calls are highly varied. They come from adults, young people, grandparents, parents and neighbours, from people of different social class and ethnic backgrounds from all over Britain. They can be asking for advice, reporting abuse, requiring counselling. Issues are varied in severity. They average something over 15 minutes although some last for as long as an hour. Where serious abuse is suspected the CPO will follow the call directly with a call to the relevant police force, or, more often, Social Services.

Calls were recorded on minidisk and then digitized for transcription and analysis. All participants to the study consented to their calls being recorded for research and training purposes. CPOs only recorded the call if they were satisfied that informed consent had been given. The calls were transcribed initially by a transcription service. These transcripts were refined using the transcription system developed by Gail J efferson (J efferson, 2004) for particular research studies by the second author. Analysis worked with the combination of digitised recording and 
transcript. The corpus is continually developing but contained more than 250 calls at the time of writing. For more details on methodological, applied or political aspects of the project see Hepburn (2004, in press), Hepburn \& Potter (2003). We will describe further relevant details as we go along.

\section{Cognition: Knowledge and attitude}

Psychologists are often interested in what people know, and what their attitudes are to things. And they have developed a range of more or less sophisticated procedures for testing knowledge and assessing attitudes. For discursive psychologists, in contrast, the starting place is not what people do or do not know and what attitudes they do or do not have, but how knowledge and attitude figure in interaction in particular settings. That is, what kind of things are these for the participants and how are they relevant, or not, to some activities. We will clarify these issues by describing a study of the opening activities in a corpus of the calls (Potter \& Hepburn, 2003). Let us emphasise that we have not started with these psychological notions, rather we have started with an attempt to explicate what is going on in the interaction.

For this analysis we worked initially with a corpus of 40 call openings. These were refined from the full collection because they included the core NSPCC practice of reporting abuse. We eliminated calls asking for counselling, offering to donate money, and passing information between different NSPCC sites and focused only on callers ringing about suspected abuse to a $3^{\text {rd }}$ party.

There is a lot of complexity in the early actions performed in calls; we will focus on an element we have called a C-construction. C-constructions often involve what might loosely be called 'expressions of concern' (hence C-construction). Let us start with an example to help make sense of what they are doing and how they relate 
to these questions of knowledge and attitude. The following extract comes from the start of a call reporting abuse - the C-constructions are arrowed. The ethics exchange has been removed to save space. The transcription conventions are described in an appendix.

\section{Extract 1 LB neighbour concern}

( (phone rings))

CP0: Hello NSPCC Helpline can I help you:?

Caller: Good after[ noon >I won]der if $y^{\prime}$

CPO: $\quad[(($ clears throat $))]$

could $<$. hhh

CPO: $\quad[\underline{Y e}: \mathrm{s}$ certainly:, ]

Caller: $\quad$ [I'm concerned about- $] \quad \leftarrow 1$

CPO: $\quad$ Yeh,

$(0.2)$

. $\mathrm{h}$

Caller: about a child that lives next

door to me.

CPO :

Tk.h ri::ght, could-before you go on

( (ethics exchange))

CPo: $\uparrow o \downarrow k a y:$ fine yeh go on:, sorry to stop you,

Caller: $\quad$ Yeah $I^{\prime} m-I^{\prime} m$ concerned about ${ }^{\circ} h^{\circ}(0.2) \quad \leftarrow 2$

my next door neighbours an they got a

little girl about six. an she's

always cry:in',

$(0.2)$

. Hh

CPO: $\quad$ R $[i: g h t$,

Caller: [I can] hear them through the wa:ll now

an mum's shoutin at 'er like anything. 
We will start with a number of observations about this extract.

First note that at line 14 the CPS says before you go on', thereby treating the caller as having more to say and being about to go on to say it. This directly follows the first C-construction and so treats it as incomplete. The CPO's 'sorry to stop you' (line 16) treats the caller as having been stopped from something. Second, note the CPO's 'right' on 14 and again on line 23. Of particular interest for us is what these turns are not doing. They are not assessments of the prior turn, nor are they moves to new business. They are simply acknowledgement tokens (Schegloff, 1982). Taken together, these things show that the $\mathrm{CPO}$ is treating the $\mathrm{C}$-construction as the start of something rather than something that is complete. 
The third point to note is that after the intrusion of the ethics exchange the caller resumes with a further $\mathrm{C}$-construction. This suggests that the $\mathrm{C}$-construction is structurally important for the early activities of the call. After the intrusion the activities are restarted with the $\mathrm{C}$-construction. The fourth point to note is that the caller continues after the CPO's acknowledgement token (line 23) with a range of descriptions that suggest violence and abuse, and attend to his knowledge of events and motive for calling.

Let us try and specify more precisely what are C-constructions doing, and therefore why they are important for the unfolding of the call.

1. C-constructions are prefacing moves.

As we have noted, C-constructions are hearably incomplete. They are treated by both caller and CPO as elements of talk that project a possibly extended set of turns. The CPO's acknowledgement tokens treat these turns as, at least potentially, appropriate to the institutionally relevant issues.

2. C-constructions project collaborative unpacking of the abuse description.

C-constructions project collaborative unpacking by not starting with a definitive claim about the status of the abuse. Instead, they operate by invoking a concern (or similar 'psychological' item), which can be worked up as more (or less) definitive in the course of conversation with the CPO. The caller starts with a stance that is open with respect to what actions the NSPCC will respond with.

3. C-constructions display the caller's (appropriate) stance.

C-constructions display the callers 'attitude' toward the object of the call, typically some kind of abuse. The topic is treated as serious, potentially damaging or upsetting. Conversely, and relevantly here, this object is not treated as something that the caller feels good about, are entertained by, or get pleasure or sexual 
excitement from. The C-construction is the caller's first opportunity to establish appropriate motivations for making the call.

4. C-constructions manage knowledge asymmetry.

Constructions orient to, and manage, a basic asymmetry. The caller is treated by both parties as knowing about the particular events and actions that they are calling about. The $\mathrm{CPO}$ is treated by both parties as knowing about the procedures of child protection work, the policies of the NSPCC, what reports should be acted on. This is similar to the situation in medical consultations where patients are treated as knowing about their particular symptoms and doctors are treated as knowing about medicine (Gill, 1998). The C-construction is a terrific way of managing the potential difficulties that the asymmetry throws up. In projecting the unpacking of concerns the caller allows the child protection status of the report to be decided by the CPO. In doing acknowledgement tokens (e.g. line 31) and follow up questions (e.g. lines 36-8).

In terms of attitude and knowledge we can see how both of these things appear as participants' issues and constructions. Attitude is displayed with a Cconstruction, and it is embedded as a practical part of the interaction. It is locally relevant rather than something that the speaker necessarily carries around as a fully formed mental object. Its production is fitted to the task at hand, of reporting abuse. Likewise with knowledge, differences are a practical issue to be managed in the interaction, and the C-construction is one effective way of doing this. Again, we should not confuse the local construction of, and management of, knowledge with the idea that these participants have particular cognitive states or entities in any simple way. Attitude and knowledge are important, but right here, right now, for the specifics of the interaction. 
Note also that the $\mathrm{C}$-construction itself has an interesting mind/reality tension built in. They simultaneously invoke mental or psychological states, and also the states of affairs in the world that generate those states. In effect, they wire in the basic mutual inference feature that is part of DP's topic. Although the word 'concern' is an item that does this job very effectively, in our analysis we found a range of other psychological objects that could be used instead. For example, the word 'worried' could be used to do this job, as could an idiom such as 'I'm going out of my bleedin head' or 'gut feeling' (see Potter, 2005).

We can see in this example the way psychological matters are bound up with the practical and institutional business of the helpline. We need to understand attitude and knowledge as matters of participant concern that are produced and attended to for their local relevance. Likewise C-constructions such as I'm a bit concerned' and 'it's a gut feeling' have a subtle institutional job of managing the caller's appropriate stance and the speakers' knowledge asymmetries, as well as projecting collaborative unfolding of the report.

\section{Perception: Noise and Hearing}

A central feature of cognitive psychology is that the person is seen to be receiving information through the perceptual system, and this information is then processed. Perception is seen as something fundamental, often bound up with physiology and mechanical processes. Although there has been a tradition of social perception for many years this has typically been conceptualized in terms of 'higher level' cognitive processes acting on perceptual 'input' when other people or social groups are the 'stimulus material' (Zebrowitz, 1990).

Recently there has been rather different tradition of work that that has considered 'perception' as a feature of situated practices. For example, Goodwin and 
Goodwin have studied situations where airline workers, say, or oceanographers 'see' particular planes or features of the ocean floor (Goodwin, 1995; Goodwin \& Goodwin, 1996). Goodwin suggests that 'seeing' involves a range of criteria, and is oriented to particular local practices. Picking up from this alternative tradition, Stokoe and Hepburn (2005) worked with a corpus of the NSPCC materials that included references to noise. Rather like Goodwin's studies of seeing, the aim was to study hearing. In this case, however, the topic was not professional hearers (audiometrists, say, or musicians) but the constructions of sounds in the reporting of abuse.

Let us illustrate this with an example. The extract below starts immediately after the caller has been taken through the ethics exchange.

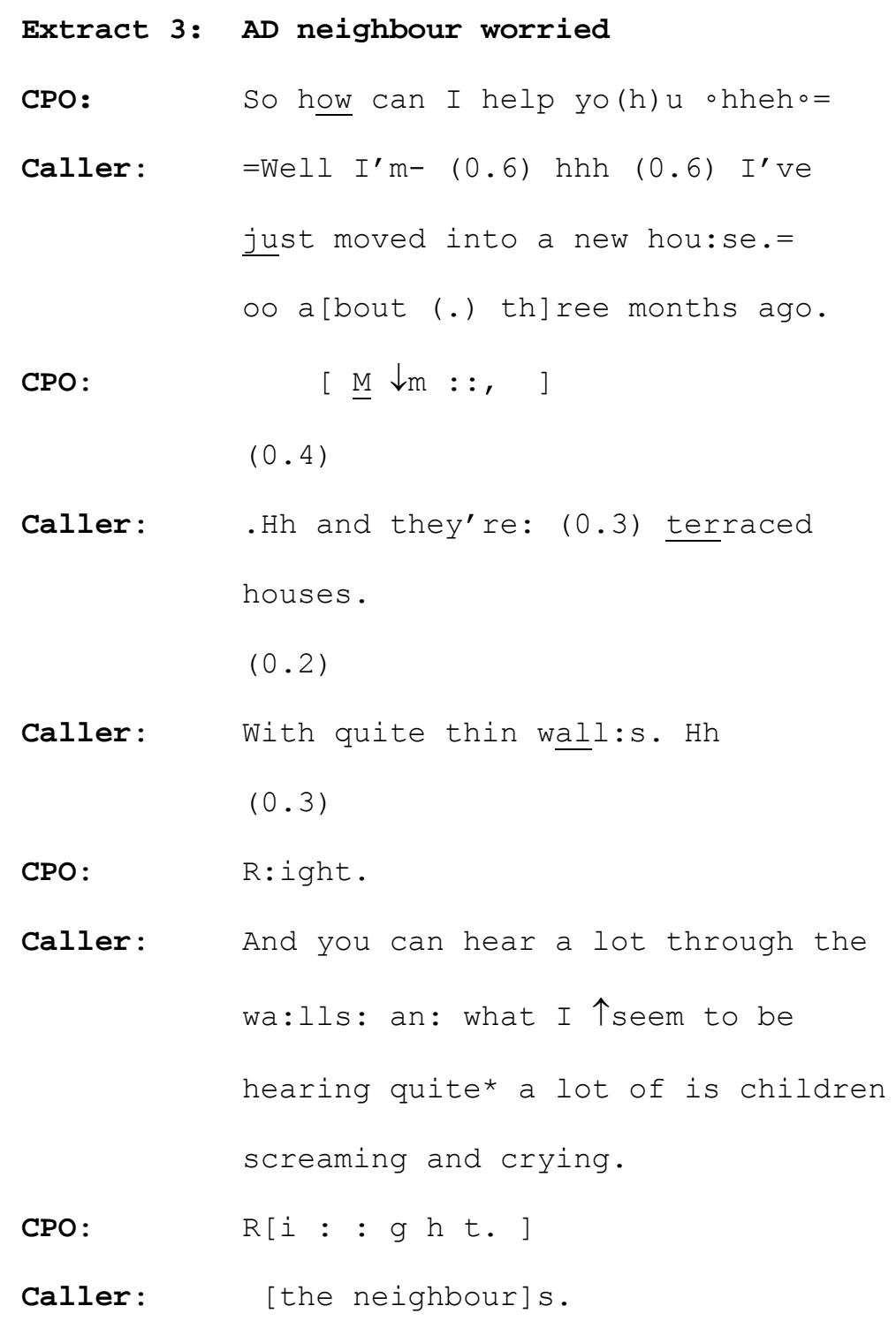




\section{Caller:}

CPO :

CPO :

Caller :

[An I'm gettin] a bit c(h) onc(h)erned.

CPO :

$(0.4)$

Caller :

R $[i: g h$ t. $]$

Let us offer a number of observations about this extract and how the various noise constructions are operating.

By describing her house as 'terraced' and having 'thin walls' (lines 7 and 10) the caller starts to manage both the epistemic status of her reports and her identity as a listener. She then spells out the implications with 'you can hear a lot through the walls' (lines 13-4). Note here the way this is constructed: 'you can hear', not 'I can hear', 'I am able to hear', 'if I am really quiet I can pick up.... The construction presents the hearing in scripted terms (see above, and Edwards, 1997). This presents it as an anybody hearing. Put another way, it heads off the idea that she spends time carefully trying to listen to what is going on; she is not a busybody.

The first specific noise construction is done cautiously:

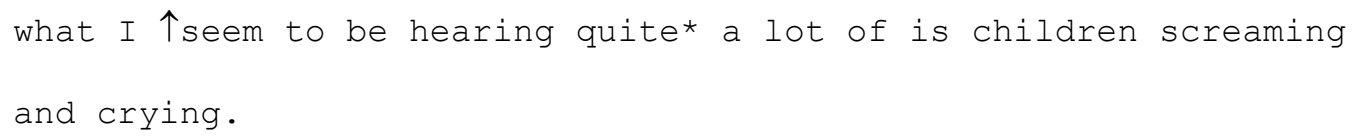

The 'seem to be hearing' displays the caller as not rushing to conclusions and allows any confirmation of NSPCC relevance to be arrived at collaboratively. The 
construction 'screaming and crying' is also interesting, as in other data sets examined the construction 'crying and screaming' was much more common (see Stokoe \& Hepburn, 2005). It is possible that more common 'crying and screaming' would make available the inference that what is heard is a problem child. However, 'screaming' followed by 'crying' makes available the inference that they have been first frightened or hurt and then responding to this event with tears.

The second noise construction also attends to the passivity of the hearing. The caller is not trying hard to hear what is going on next door, as a 'nosey neighbour' might. Rather she is 'sitting here in my living room' (lines 25-6). She constructs herself as doing what an ordinary person would do. Note the importance that this is treated as having for the narrative, because the caller breaks off what would probably have been 'just heard' (line 25) and inserts the living room description. In the actual noise description the caller reports direct speech: 'please don't do: that. please don't do: that. dad. dad.' (lines 27-8). This does a number of things. First, reporting speech like this as if verbatim (we have no record, of course), manages the objectivity of the caller. They are not going beyond what they have heard. The rather flat 'as if read out' delivery further contributes to this sense of being objective. Second, the words present a puzzle. What would make a child say those particular words? One solution to the puzzle is that the father is doing something abusive to the child. By offering the puzzle rather than the conclusion the caller further bolsters her status as a reliable witness, and allows the upshot to be a collaborative production with the CPO.

In their study Stokoe and Hepburn (2005) bring out an important further level of detail in the noise reporting by comparative analysis with set of calls to a neighbour mediation service. There too, there are a large number of calls reporting noise from neighbours and children. However, calls to the mediation service 
typically construct what they can hear as noise, as well as being inappropriate (e.g. over loud or very late at night). Such reports are systematically different from the NSPCC abuse reports. In the NSPCC calls the callers do not complaining - they are concerned (note the C-construction in line 21) about the child, not bothered for their own comfort. Their motives are produced, in the detail of the noise reporting, as altruistic rather than selfish.

What we see in this study is the way aspects of perception - sound, things that are heard, are constructed in specific ways as parts of the discrete conversational practices. There are subtle but systematic differences when calling a child protection helpline and calling a neighbour mediation line. These reflect the hearing of 'unwarranted disturbance' or 'indications of child abuse'. In this setting hearing is public and interactional. This shows how 'perception', whatever its biological underpinning, is inextricably bound up with practices of interaction.

\section{Emotion: Crying and Empathy}

Emotion is a theoretically interesting topic for discursive research as it too is something of a 'hard case'. That is, it is often treated as something close to biology, something lying underneath language and maybe even culture. Often in social psychology emotion is treated as a causal variable that exerts a distorting effect on cognition (Park \& Banaji, 2000). However, Edwards (1997) has suggested that the very category 'emotion' needs to be treated cautiously. The boundaries and contrasts of what makes up 'emotion' are different across cultures and settings. Indeed the category 'emotion' itself is a feature of a particular modern and Western idea of the person. As Edwards (1999) suggests:

Emotions are not only contrasted with cognitions (whether rational or not), both in 'folk' and in professional psychology, but there are also cognitive 
theories of emotions, and indeed cognitive models that virtually do away with, or explain away, emotion categories altogether. But there are also emotionbased explanations of cognition, of what people think, what they think about, and why they think one thing rather than another (because of envy, jealousy, prejudice, obsession, etc.).

Edwards has used ideas from conversation analysis, cultural anthropology and constructionism, as the basis for a respecification that focuses research on: (a) the use of 'emotion' categories; (b) orientations to objects and actions as 'emotional' and (c) displays of 'emotion'. Some of these features appear in a further development of our child protection project where callers' crying and CPO's responses to crying are the topic of analysis (Hepburn, 2004).

One of the features of psychological work on crying is that it has overwhelmingly worked with participants' reports of crying (in questionnaires or rating scales). There is no work that uses direct observation, or attempts to provide situated descriptions of crying. This meant that one of the early research tasks was to develop an extension to the J effersonian transcription scheme that would represent different features of crying such as sobs, whispers, wet sniffs and wobbly voice (see appendix for details). This fine grained description of crying provides a way of seeing how the different activities in crying and crying recipiency are organized together. We can illustrate this with the following extract. Various characteristic elements of crying on the helpline are highlighted such as caller apologies (A), and CPO actions such as 'right-thing' descriptions (RT), 'take-your-times' (TYT) and what we have termed 'empathic receipts' (ER).

Extract 4: JK distraught dad

1 Caller: >. Hhih . hhihhh<

2 CPO: D'you want- $\mathrm{d}^{\prime} \mathrm{y}^{\prime}$ wann'ave [a break for a $]$ moment. $=\leftarrow$ TYT 
Caller:

$=>$ hhuhh hhuhh $<$

$(0.6)$

Caller: .shih

$(0.3)$

Caller: $\quad \circ \mathrm{k}(\mathrm{hh}) \mathrm{ay}^{\circ \circ}$

$(1.8)$

Caller: $\quad$.shih >hhuh hhuh $[\mathrm{h}]<$

CPO :

$[\mathrm{S}]$ ' very har: d when

and [you're- ]

(.) you're tal:kin about it.

$\leftarrow E R$

Caller:

$[>. h h i h<]$

$(0.8)$

Caller: >. Hhuh . HHuh<

$(2.1)$

Caller: .shih

$(0.2)$

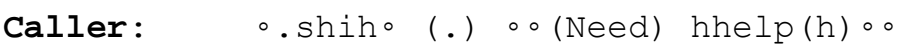

$(2.5)$

Caller: .HHhihhohh。

$(0.5)$

Caller: HHhuhh $>$.hih. hih<

$(0.7)$

CPO :

.Htk.hh Well you're doing what you can now to

are: $n^{\prime} t$ you

$\leftarrow \mathrm{RT}$

Caller: .Skuh (.) Huhhhh

$(0.5)$

Caller: $\circ \circ:^{\prime} m$ not the (hehheh) re. Hho。

$(3.2)$ 


\begin{tabular}{|c|c|c|c|}
\hline 33 & Caller: & Shih & \\
\hline 34 & & $(0.4)$ & \\
\hline 35 & Caller: & $\sim \uparrow^{\prime} \mathrm{m}$ 个 $\underline{\mathrm{sor}} \boldsymbol{\underline { y }} \cdot \sim$ & $\leftarrow \mathrm{A}$ \\
\hline 36 & CPO : & An they als- well E-E-Eddie obviously al- thought & $\leftarrow \mathrm{RT}$ \\
\hline 37 & & you were the person to contact to get he:lp. & $\leftarrow \mathrm{RT}$ \\
\hline 38 & Caller: & Yeh. hh & \\
\hline 39 & CPO : & F'which (.) ye know he turned to you: .hh & $\leftarrow \mathrm{RT}$ \\
\hline 40 & & $(0.7)$ & \\
\hline 41 & Caller: & . $\operatorname{Hh}\left[h^{\circ} h h h^{\circ} \quad\right]$ & \\
\hline 42 & CPO : & {$\left[T^{\prime}\right.$ help 'im. $]=\underline{\text { didn't he. }}$} & $\leftarrow \mathrm{RT}$ \\
\hline 43 & Caller: & $\circ \circ Y h h e h h h \circ \circ$ & \\
\hline 44 & CPO : & So 'e saw you as a person who could help in this & $\leftarrow \mathrm{RT}$ \\
\hline 45 & & situa [tion ] for him:. & $\leftarrow \mathrm{RT}$ \\
\hline 46 & Caller: & {$[$. Shih $]$} & \\
\hline 47 & & $(0.9)$ & \\
\hline 48 & Caller: & .Hdihhhh hhhuhh & \\
\hline 49 & & $(0.2)$ & \\
\hline 50 & Caller: & H个oh: $s(h)$ orry. & $\leftarrow \mathrm{A}$ \\
\hline 51 & & $(0.4)$ & \\
\hline 52 & CPO : & .Htk s'个oka:y. kay. & \\
\hline 53 & & $(1.3)$ & \\
\hline 54 & Caller: & . SKUH & \\
\hline 55 & & $(0.3)$ & \\
\hline 56 & CPO : & It's distressing but it's also quite a shock & $\leftarrow \mathrm{ER}$ \\
\hline 57 & & isn't it I guess [(for you)] & $\leftarrow E R$ \\
\hline 58 & Caller: & [.HHHHhih] hh HHHhuhhhh & \\
\hline 59 & & $(1.7)$ & \\
\hline 60 & Caller: & ((swallows)) ${ }^{\circ}$ Hhhoh dhear. ${ }^{\circ}$ & \\
\hline
\end{tabular}


Once we have a description that allows this level of detail to be revealed we can start to observe a range of interesting features about the way the extract develops. First, note the way the take-your-time in line 2 is occasioned by the caller's sobbing that starts in line 1 and continues through to line 4 . We can see how delicate the mutual attention in this interaction is as, despite the sobbing, the caller responds to the takeyour-time with a whispered 'khhay' (line 8).

Second, note further on in the sequence the caller's wobbly voiced apology (line 35). We might think that the caller is apologising for the transgressive nature of sobbing with a stranger or something similar. However, a careful examination of where apologies appear in crying sequences suggests that they are more likely to be apologies for disruption of ongoing actions or failing to provide normatively expected contributions. That is, they are explicated better by understanding conversational organization. For example, in this case the CPO's assessment in $26-8$ is followed by an extremely quiet and very disrupted second assessment on 31 (the normatively expected turn). The following delay from the $\mathrm{CPO}$ would allow the turn to be recycled, and the apology could be specifically apologising for the absence of this recycling.

Third, note the right-thing descriptions on 26-8 and through 36-45. These are constructed from information already provided by the caller, redescribed to present him having done the right thing. Such descriptions seem designed to reassure the caller and move him out of crying. These descriptions are often accompanied by tag questions (e.g. 28 and 42), which may be designed to move the caller out of crying by encouraging agreement with the right-thing description.

Finally let us consider the interesting topic of empathy. Recently some researchers have started to develop an interactional account of empathy (Pudlinski, 2005; Ruusuvuori, in press). We have marked segments of this extract where the 
CPO does 'empathic receipts'. The category empathy comes from psychology rather than interaction analysis; however, there are a cluster of features that tend to go together in empathic receipts. Typically there is a formulation of the experience from the recipient's point of view or of the recipient's 'mental state'. Thus on line 11 there is the formulation it's 'very hard' and on line 56 the formulation 'it's distressing but it's also quite a shock'. Interactional contributions such as this are potentially tricky as the speaker is offering a version of something that the recipient is normally expected to know best. Features such as the tag questions (12 and 57) and displays of epistemic caution (e.g. 'T guess' on 57) may be a way of managing this.

More generally, although emotion is often thought of as something that is beyond the purchase of DP, studies of this kind show the way that issues and actions which we understand as emotional can be tractable to interaction analysis. This is not surprising once we remind ourselves of the practical and communicative role that emotions play in social life (Planalp, 1999). DP offers the possibility of understanding the various phenomena loosely glossed as emotion in terms of what they are doing and where they appear in peoples' lives.

\section{Discourse, psychology and interaction}

Work in contemporary DP is made up a number of closely related themes.

These NSPCC studies illustrate a number of them:

- They are studies of the procedures through which the psychological implications of talk are managed.

- They consider the practical use of the mental thesaurus (terms such as 'concern', 'hearing', 'screaming'), although it simultaneously makes problematic a simple distinction between a mental thesaurus and other terms. 
- They are studies that respecify core theoretical notions from orthodox cognitive and social cognitive psychology (knowledge, attitudes, perception, emotions).

- They focus on the 'embodiment' of psychological states in displays, for example in the sobs and sniffs of crying.

- They address the relationship of psychological and institutional issues, exploring the way the business of the helpline (reporting abuse, orienting to expertise, and so on) is actively accomplished, in part by the use of psychological terms and practices.

There is another theme of DP research that is focused specifically on psychological research methods in practices. It studies both the interactional accomplishment of the method and the constitution of particular findings. There has not been space to overview this work here (but see Antaki, 2005; Puchta \&Potter, 2002; and, from a more specifically CA perspective, Schegloff, 1999).

In addition to these research themes there is a developing interesting in the potential for DP doing practical or applied work. For a discussion of the problems and possibilities here see Hepburn (2005) as well as a range of the contributions to Hepburn \& Wiggins (forthcoming).

In general then, discursive psychology offers a way of theorizing and analyzing psychology as a feature of people's practices. It starts with records of what people actually do. In the examples discussed here we have focused on interaction on a helpline, but DP work has been done in a wide range of different settings, and the research is limited only by the imagination of the researcher and the possibility of gaining appropriate access. It offers a picture of psychology that is embedded in practices rather than abstracted from those practices. 


\section{Appendix - Transcription notation}

The transcription notation is most fully described in J efferson (2004). Hepburn (2004) has developed symbols specifically for dealing with features of crying.

\section{General transcription notion}

[ ]

$\uparrow \downarrow$

$\rightarrow$

Underlining

CAPITALS

${ }^{\circ} \uparrow$ I know it, ${ }^{\circ}$

that's ræight.

(.)

$(($ text))

she wa::nted

hhh

.hhh
Square brackets mark the start and end of overlapping speech.

Vertical arrows precede marked pitch movement, over and above normal rhythms of speech. They are for marked, hearably significant shifts. The aim is to capture interactionally significant features, hearable as such to an ordinary listener.

Side arrows are not transcription features, but draw analytic attention to particular lines of text.

signals vocal emphasis; the extent of underlining within individual words locates emphasis, but also indicates how heavy it is.

mark speech that is obviously louder than surrounding.

'degree' signs enclose obviously quieter speech (i.e., hearably produced-as quieter, not just someone distant).

Asterisks precede a 'squeaky' vocal delivery.

Numbers in round brackets measure pauses in seconds (in this case, 4 tenths of a second).

A micropause, hearable but too short to easily measure.

Additional comments from the transcriber, e.g. context or intonation.

Colons show degrees of elongation of the prior sound; the more colons, the more elongation.

Aspiration (out-breaths); proportionally as for colons.

Inspiration (in-breaths); proportionally as for colons. 
Yeh,

$y^{\prime} k n o w ?$

Yeh.

bu-u-

>he said<

solid.=

=We had

heh heh

sto(h)p i(h)t

Features of crying

${ }^{\circ}$ help ${ }^{\circ \circ}$

.shih

.skuh

q grandson

$\uparrow \uparrow$ Sorry

k(hh)ay

hhhelp

Huhh .hhih

Hhuyuhh

$>$ hhuh<
'Continuation' marker, speaker has not finished; marked by fall-rise or weak rising intonation, as when enunciating lists.

Question marks signal stronger, 'questioning' intonation, irrespective of grammar.

Periods (full stops) mark falling, stopping intonation ('final contour'),

irrespective of grammar.

hyphens mark a cut-off of the preceding sound.

'greater than' and 'lesser than' signs enclose speeded-up talk.

'Equals' signs mark the immediate 'latching' of successive talk, whether of one or more speakers, with no interval.

Voiced laughter. Can have other symbols added, such as underlinings, pitch movement, extra aspiration, etc.

Laughter within speech is signalled by h's in round brackets.

Whispering - enclosed by double degree signs

Wet sniff

Snorty sniff

Wobbly voice - enclosed by tildes

High pitch - represented by one or more upward arrows

Aspiration in speech - an 'h' represents aspiration:

in parenthesis indicates a sharper more plosive sound

outside parenthesis indicates a softer more breathy sound

Sobbing - combinations of 'hhs', some with full stops before them to indicate inhaled rather than exhaled, many have voiced vowels, some have voiced consonants. If sharply inhaled or exhaled - enclosed in the 'greater than/less than' symbols $(><)$ 


\section{References}

Ajzen, I. (1991). The theory of planned behaviour, Organizational Behavior and Human Decision Processes, 50, 179-211.

Antaki, C. (2006). Producing a cognition, Discourse Studies, *, **_**.

Billig, M. (1992). Talking of the royal family. London: Routledge.

Billig, M. (1996[1987]). Arguing and Thinking: A Rhetorical Approach to Social Psychology (2nd edn.). Cambridge: Cambridge University Press.

Coulter, J . (1999). Discourse and mind. Human Studies, 22: 163-181.

Coulter, J . (2005). Language without mind. In te Molder, H. \& Potter, J . (Eds.). Conversation and cognition (pp. 79-92). Cambridge: Cambridge University Press.

Edwards, D. (1994). Script Formulations: A Study of Event Descriptions in Conversation. J ournal of Language and Social Psychology, 13 (3), 211-247.

Edwards, D. (1995). Two to Tango: Script Formulations, Dispositions, and Rhetorical Symmetry in Relationship Troubles Talk. Research on Language and Social Interaction, 28 (4), 319-350.

Edwards, D. (1997). Discourse and cognition. London and Beverly Hills, CA: Sage.

Edwards, D. (1999). Emotion discourse. Culture \& Psychology, 5 (3), 271-291.

Edwards, D. (2003). Analysing racial discourse: The discursive psychology of mindworld relationships. In H. van den Berg, M. Wetherell \&H. HoutkoopSteenstra (Eds), Analysing race talk: Multidisciplinary approaches to the interview (pp. 31-48). Cambridge: Cambridge University Press.

Edwards, D. (in press). Managing subjectivity in talk. In A. Hepburn and S. Wiggins (Eds). Discursive Research in Practice: New Approaches to Psychology and Interaction. Cambridge: Cambridge University Press. 
Edwards, D. \& Potter, J. (1992). Discursive psychology. London: Sage.

Edwards, D. \& Potter, J . (1999). Language and causal attribution: A rejoinder to Schmid and Fiedler, Theory \& Psychology, 9, 849-63.

Gilbert, G. N. \&Mulkay, M. (1984). Opening Pandora's box: A sociological analysis of scientists' discourse. Cambridge: Cambridge University Press.

Gill, V. (1998). Doing attributions in medical interaction: Patients' explanations for illness and doctors' responses, Social Psychological Quarerly, 61, 342-360.

Goodwin, C. \& Goodwin, M.H. (1996). Seeing as situated activity: Formulating planes. In Engeström, Y. \& Middleton, D. (Eds) Cognition and communication at work (pp. 61-95). Cambridge: Cambridge University Press.

Goodwin, C. (1995) Seeing in depth, Social Studies of Science, 25, 237-74.

Harris, R. (1988). Language, Saussure and Wittgenstein: How to play games with Words. London: Routledge.

Hepburn, A. (2003). An introduction to critical social psychology. London: Sage. Hepburn, A. (2004). Crying: Notes on description, transcription and interaction. Research on Language and Social Interaction, 37, 251-290.

Hepburn, A. (2005, in press). Getting closer at a distance: Theory and the contingencies of practice, Theory \& Psychology.

Hepburn, A. \& Potter, J . (2003). Discourse analytic practice. In C. Seale, D. Silverman, J. Gubrium \& G. Gobo (Eds). Qualitative research practice (pp. 180-196). London; Sage.

Hepburn, A. \&Wiggins, S. (2005). Size matters: Constructing accountable bodies in NSPCC helpline and family mealtime talk, Discourse \& Society, 16, 625-647. Hepburn, A. \&Wiggins, S. (Eds)(forthcoming). Discursive psychology in practice. Cambridge: Cambridge University Press. 
J aworski, A. \& Coupland, N. (Eds.)(1999). The Discourse Reader. London; Routledge.

J efferson, G. (2004). Glossary of transcript symbols with an introduction. In G.H. Lerner (Ed.). Conversation analysis: Studies from the first generation (pp. 13-31). Amsterdam: John Benjamins.

Lawes, R. (1999). Marriage: An analysis of discourse. British J ournal of Social Psychology, 38, 1-20.

Park, J ., \&Banaji, M. R. (2000). Mood and heuristics: The influence of happy and sad states on sensitivity and bias in stereotyping, J ournal of Personality and Social Psychology, 78, 1005-1023. heuristics: The influence of happy and sad states on

Potter, J . (1996). Representing reality: Discourse, rhetoric, and social construction. London and Thousand Oaks, CA: Sage.

Potter, J . (2003a). Discourse analysis and discursive psychology. In P.M. Camic, J .E. Rhodes and L. Yardley (Eds). Qualitative research in psychology: Expanding perspectives in methodology and design (pp. 73-94).

Washington: American Psychological Association.

Potter, J . (2003b). 'Discourse analysis', in M. Hardy \&A. Bryman (Eds) Handbook of Data Analysis (pp. 607-624). London; Sage.

Potter, J . (2004). 'Discourse analysis as a way of analysing naturally occurring talk', in D. Silverman (Ed.) Qualitative Analysis: Issues of theory and method, $2^{\text {nd }}$ Edition (pp. 200-221). London: Sage.

Potter, J . (2005). A discursive psychology of institutions, Social Psychology Review, 7, 25-35. 
Potter, J . \&Edwards, D. (2001a). Sociolinguistics, cognitivism and discursive psychology. In N. Coupland, S. Sarangi, \& C. Candlin (Eds.) Sociolinguistics and Social Theory (pp. 88-103). London; Longman.

Potter, J . \& Edwards, D. (2001b). Discursive social psychology. In W. P. Robinson and H. Giles. (Eds). The new handbook of language and social psychology (pp. 103-118). London; J ohn Wiley \& Sons Ltd.

Potter, J . \& Edwards, D. (2003). Rethinking cognition: On Coulter, discourse and mind, Human Studies, in press.

Potter, J . \& Hepburn, A. (2003). I'm a bit concerned - Early actions and psychological constructions in a child protection helpline, Research on Language and Social Interaction, 36, 197-240.

Potter, J . \& Hepburn, A. (2005). Qualitative interviews in psychology: problems and possibilities, Qualitative research in Psychology, 2, 38-55.

Potter, J . \& Wetherell, M. (1988). Accomplishing attitudes: Fact and evaluation in racist discourse. Text, 8 (1-2), 51-68.

Potter, J . \& Wetherell, M. (1987). Discourse and social psychology: Beyond attitudes and behaviour. London: Sage.

Puchta, C. \& Potter, J . (2002). Manufacturing individual opinions: Market research focus groups and the discursive psychology of attitudes, British J ournal of Social Psychology, 41, 345-363.

Pudlinski, C. (2005). Doing empathy and sympathy: Caring responses to troubles tellings on a peer support line, Discourse Studies, 7, 267-288.

Ruusuvuori, J ( (in press). Empathy and sympathy in action: Attending to patients' troubles in Finnish homeopathic and gp consultations, Social Psychology Quarterly. 
Sacks, H. (1992). Lectures on conversation. Vols. I \& II, edited by G. J efferson. Oxford: Basil Blackwell.

Schegloff, E.A. (1982). Discourse as an interactional achievement: Some uses of 'uh huh' and other things that come between sentences. In D. Tannen (Ed.), Georgetown University Round Tabel on Language and Linguistics, 1981: Text and Talk. Washington, DC: Georgetown Univesity Press.

Schegloff, E.A. (1999) Discourse, pragmatics, conversation, analysis, Discourse Studies 1, 405-36.

Schmid, J ., \& Fiedler, K. (1999). A parsimonious theory can account for complex phenomena: A discursive analysis of Edwards and Potter's critique of nondiscursive language research. Theory \& Psychology, 9(6), 807- 822.

Stokoe, E. H. \&Hepburn, A. (2005). 'You can hear a lot through the walls': Noise formulations in neighbour complaints, Discourse \& Society, 16, 647-674.

te Molder, H. \&Potter, J . (Eds) (2004). Conversation and Cognition. Cambridge: Cambridge University Press.

Wetherell, M. and Edley, N. 1999. Negotiating hegemonic masculinity: imaginary positions and psycho-discursive practices', Feminism and Psychology, 9, 3: 335-56.

Wetherell, M. and Potter, J . (1992). Mapping the Language of Racism: Discourse and the Legitimation of Exploitation. Hemel Hempstead: Harvester/Wheatsheaf and New York: Columbia University Press.

Wetherell, M. Taylor, S. \&Yates, S. (Eds)(2001a). Discourse theory and practice: A reader. London; Sage.

Wiggins, S. \&Hepburn, A. (forthcoming). Food abuse: Mealtimes, helplines and troubled eating. In A. Hepburn \& S. Wiggins (Eds). Discursive research in practice. Cambridge: Cambridge University Press. 
Wiggins, S. \& Potter, J . (2003). Attitudes and evaluative practices: Category vs. item and subjective vs. objective constructions in everyday food assessments, British J ournal of Social Psychology, 42, 513-531.

Wittgenstein, L. (1953). Philosophical investigations. Oxford: Blackwell.

Wood, L A and Kroger, R O (2000) Doing Discourse Analysis: Methods for Studying Action in Talk and Text. Thousand Oaks, Ca: Sage

Zebrowitz, L.A. (1990). Social perception. Buckingham: Open University Press. 